\title{
A NOVA GASOLINA S50 E O PROCONVE L6
}

\author{
Rogério N. de Carvalho ${ }^{1}$, Pedro C. Vicentini ${ }^{1}$, Ricardo A. B. de Sá ${ }^{1}$, \\ Antônio Carlos S. Villela ${ }^{1}$, Sérgio W. Botero ${ }^{1}$ \\ ${ }^{1}$ Petróleo Brasileiro S. A. - PETROBRAS \\ E-mails: rogerio.carvalho@petrobras.com.br, pcvicentini@petrobras.com.br, \\ rsa@petrobras.com.br, antonio.villela@petrobras.com.br, \\ sergio.botero@petrobras.com.br
}

\section{RESUMO}

O presente trabalho reporta os resultados dos estudos comparativos realizados no Centro de Pesquisas e Desenvolvimento da Petrobras - CENPES sobre os efeitos da nova gasolina S50 nas emissões e no consumo de combustível dos veículos atuais, e faz uma projeção da sua utilização nos veículos que atenderão a fase L6 do PROCONVE a partir de 2014.

Serão apresentados resultados comparativos de ensaios de emissões e consumo realizados com a gasolina atual e com uma formulação experimental de gasolina S50, cujo perfil se aproxima do que será produzido e disponibilizado para o mercado brasileiro a partir de 2014 .

\section{INTRODUÇÃO}

Desde a instituição no Brasil do Programa de Controle da Poluição do Ar por Veículos Automotores - PROCONVE, em $1986^{[1]}$, sob a coordenação do IBAMA, a indústria da mobilidade nacional vem introduzindo subsequentes avanços tecnológicos para atender aos limites de emissões de gases poluentes impostos pelo programa. Os veículos passaram a ser equipados com motores e sistemas cada vez mais avançados para o controle da injeção de combustível e para o pós-tratamento dos gases de escapamento. Da mesma forma, os requisitos de qualidade dos combustíveis também foram sendo aprimorados e várias modificações nas suas especificações foram implementadas.

Essas ações permitiram substanciais reduções nas emissões dos gases legislados. De acordo com o $1^{\text {o }}$ Inventário Nacional de Emissões Atmosféricas por Veículos Automotores Rodoviários ${ }^{[2]}$, estima-se que as emissões veiculares de monóxido de carbono (CO) foram reduzidas de 5,6 milhões de toneladas em 1991 para 1,5 milhões de toneladas em 2009. Nesse mesmo período, o estudo aponta também para acentuada queda das emissões de hidrocarbonetos não metanos (NMHC), de 900 mil para cerca de 
200 mil toneladas. Reduções das emissões de óxidos de nitrogênio (NOx) também foram observadas, passando de 1,2 milhões de toneladas em 1998 para aproximadamente 900 mil toneladas em 2010.

Especificamente em relação aos veículos de passageiros e comerciais leves até $1700 \mathrm{~kg}$, equipados com motores do ciclo Otto, a fase L6 do PROCONVE entra em vigor em 2014 para os veículos novos e em 2015 para os demais, conforme estabelecido na Resolução CONAMA 415/2009 $9^{[3]}$. Desde a primeira fase (L1) o programa já estabeleceu reduções gradativas e significativas nos limites de emissões requeridos para a homologação dos veículos. Em relação à fase L5, a nova etapa do programa (L6) estabelece reduções dos limites de CO (de 2,0 para 1,3 g/km), de NOx (de 0,12 para $0,08 \mathrm{~g} / \mathrm{km}$ ), de emissões evaporativas - SHED (de 2,0 para 1,5 g/teste) e de CO em marcha lenta (de 0,5\% para 0,2\%). As emissões de NMHC e de aldeídos foram mantidas nos níveis de 0,05 e $0,02 \mathrm{~g} / \mathrm{km}$, respectivamente.

A Resolução CONAMA 415/2009 determinou ainda que novas especificações de combustíveis de referência e comerciais fossem estabelecidas, com foco principal na redução dos teores de enxofre da gasolina e do diesel. Por indicação dos fabricantes de veículos, este requisito se apresentava como sendo fundamental para o correto funcionamento dos sistemas de pós-tratamento, com durabilidade assegurada. Desta forma, a ANP (Agência Nacional do Petróleo, Gás Natural e Biocombustíveis) definiu as novas especificações da gasolina padrão para ensaios de homologação e da gasolina comercial brasileiras, com teores máximos de enxofre de $50 \mathrm{mg} / \mathrm{kg}$ (ou $50 \mathrm{ppm}$ ), comumente denominada gasolina S50. A Tabela I apresenta os limites dos teores máximos de enxofre e dos hidrocarbonetos aromáticos e olefínicos das novas gasolinas padrão e comercial S50, em comparação com as respectivas gasolinas atuais.

Tabela I

Comparação das especificações das gasolinas S50 com as gasolinas atuais.

\begin{tabular}{l|c|c|c|c}
\hline \multicolumn{1}{c|}{ Gasolinas } & $\begin{array}{c}\text { Gasolina A } \\
\text { Padrão } \\
\text { Atual }\end{array}$ & $\begin{array}{c}\text { Gasolina A } \\
\text { Padrão } \\
\text { L6 (2014) }\end{array}$ & $\begin{array}{c}\text { Gasolina C } \\
\text { Comercial } \\
\text { Atual }\end{array}$ & $\begin{array}{c}\text { Gasolina C } \\
\text { Comercial } \\
\text { L6 (2014) }\end{array}$ \\
\hline Enolução & ANP 06/2005 ${ }^{[4]}$ & ANP 21/2009 & ANP 57/2011 & ANP 38/2009 $9^{[7]}$ \\
Aromáticos (\%vol.) & 51,3 & 50 & 800 & 50 \\
Olefinicos (\%vol.) & 25,7 & 15 & 45 & 35 \\
\hline
\end{tabular}

Sabe-se que a presença de enxofre na gasolina pode causar uma diminuição instantânea da atividade catalítica do conversor e/ou levar a uma degradação da sua eficiência no longo prazo. Trabalhos anteriores do $\mathrm{CENPES}^{[8,9,10]}$ investigaram os efeitos, nas emissões de escapamento, da variação do teor de enxofre na gasolina nacional. 
Com relação ao efeito instantâneo da redução do teor de enxofre, verificaram-se ganhos importantes na redução dos principais poluentes em veículos da fase L3 e L4 do PROCONVE. No entanto, em relação à durabilidade dos sistemas catalíticos de veículos a gasolina e flex das fases L3, L4 e L5, identificou-se que fatores térmicos se mostraram preponderantes em relação à contaminação por enxofre na desativação dos catalisadores durante o acúmulo de $80.000 \mathrm{~km}^{[11,12]}$.

No presente artigo, se apresentam os resultados de novos ensaios de emissões comparativos entre a gasolina S50 e a gasolina atual em veículos representativos das fases L3, L4, L5 e L6, sem levar em consideração a durabilidade do sistema de emissões.

\section{METODOLOGIA}

\subsection{COMBUSTÍVEIS}

Como combustíveis de teste, foram utilizados uma gasolina $\mathrm{C}$ comercial, com teor de enxofre que atende à atual especificação da ANP (máximo de 800 ppm), e outra com teor inferior a $50 \mathrm{ppm}$, valor que entrará em vigor a partir de 2014. Em vista disso, esses combustíveis foram denominados "Gasolina S800" e "Gasolina S50", respectivamente. Salienta-se que a ambas foram adicionados $22 \%$ de etanol hidratado, obtendo-se uma mistura com teor intermediário ao estabelecido na legislação, que tem variado entre 20 e 25\%. A Tabela II apresenta as principais propriedades dos combustíveis testados.

Tabela II

Principais propriedades das gasolinas de teste, sem etanol.

\begin{tabular}{c|c|c|c}
\hline \multicolumn{2}{c|}{ Propriedades } & Gasolina S800 & Gasolina S50 \\
\hline \multirow{3}{*}{$\begin{array}{c}\text { Destilação } \\
\left({ }^{\circ} \mathrm{C}\right)\end{array}$} & T10 & 52,8 & 57,7 \\
\cline { 2 - 4 } & $\mathrm{T} 50$ & 93,2 & 100,2 \\
\cline { 2 - 4 } & $\mathrm{T} 90$ & 157,2 & 175,1 \\
\cline { 2 - 4 } & PFE & 196,5 & 204,1 \\
\hline \multicolumn{2}{c|}{ PVR $(\mathrm{kPa})$} & 62,1 & 48,9 \\
\hline \multicolumn{2}{c|}{ Enxofre. $(\mathrm{ppm})$} & 412 & 38 \\
\hline \multirow{2}{*}{$\begin{array}{c}\text { Hidrocarbonetos } \\
(\% \mathrm{v})\end{array}$} & Aromáticos & 21,87 & 29,92 \\
\cline { 2 - 4 } & Olefínicos & 21,33 & 24,62 \\
\cline { 2 - 4 } & Saturados & 56,80 & 45,46 \\
\hline
\end{tabular}




\subsection{VEÍCULOS}

Para realização do presente estudo foram utilizados 9 veículos leves, representando as fases L3, L4, L5 e L6 do PROCONVE de diferentes fabricantes, anos de fabricação, motorizações e tecnologias de controle de emissões. O objetivo foi observar o efeito do novo combustível em uma amostra representativa da frota de veículos em uso com características variadas. Para representar a nova fase L6, foi utilizado um veículo homologado segundo a fase L5, mas que já atende aos limites da L6.

Pelo fato de haver uma tendência de as emissões de veículos em mau estado de manutenção serem pouco sensíveis à qualidade do combustível, todos os veículos foram aprovados no teste de emissões estático (marcha lenta e $2500 \mathrm{rpm}$ ) para leitura de THC e CO, conforme estabelecido pelo IBAMA para programas de Inspeção e Manutenção (I/M) ${ }^{[13]}$. A Tabela III apresenta algumas características dos veículos utilizados nos experimentos.

Tabela III

Características dos veículos testados.

\begin{tabular}{|c|c|c|c|c|c|}
\hline Modelo & Ano & Fase PROCONVE & Cilindrada (L) & Combustível & Km inicial \\
\hline $\mathrm{V} 1$ & 2001 & L3 & 1.0 & Gasolina & 177.219 \\
\hline $\mathrm{V} 2$ & 2001 & L3 & 1.6 & Gasolina & 205.720 \\
\hline V3 & 2007 & L4 & 2.0 & Flex & 61.419 \\
\hline $\mathrm{V} 4$ & 2008 & L4 & 2.3 & Gasolina & 102.763 \\
\hline V5 & 2008 & L4 & 2.0 & Flex & 102.703 \\
\hline V6 & 2011 & L5 & 1.0 & Flex & 14.108 \\
\hline V7 & 2011 & L5 & 1.0 & Flex & 18.633 \\
\hline V8 & 2011 & L5 & 1.4 & Flex & 26.722 \\
\hline V9 & 2011 & L5/L6 ${ }^{(1)}$ & 1.6 & Flex & 11.182 \\
\hline
\end{tabular}

veículo homologado como L5, mas que já atende aos limites L6.

\subsection{ENSAIOS}

Os ensaios para medição de emissões de escapamento e autonomia urbana foram realizados em dinamômetro de chassi, com medição das emissões de escapamento (THC, $\mathrm{CH}_{4}, \mathrm{CO}$, NOx e $\mathrm{CO}_{2}$ ), segundo a Norma ABNT NBR 6601 ${ }^{[14]}$, de aldeídos (formaldeído + acetaldeído), conforme a Norma ABNT NBR $12026^{[15]}$ e de autonomia urbana, conforme a Norma ABNT NBR $7024^{[16]}$.

Para que o tratamento estatístico fosse mais efetivo e para melhor compor os resultados, as gasolinas foram testadas no mínimo três vezes em cada veículo. Para a comparação dos resultados obtidos com os combustíveis, utilizou-se a Análise de Variância (ANOVA) como ferramenta capaz de identificar a existência ou não de diferenças estatisticamente significativas $(\mathrm{p}=0,05)$. Quando esta foi detectada, procedeu-se o teste LSD (least significant difference) para a comparação das médias. 


\section{RESULTADOS}

Nas figuras 1 a 6 são apresentados os resultados médios dos ensaios de emissões de escapamento e autonomia urbana da frota testada. $\mathrm{O}$ valor indicado sobre a segunda barra de cada veículo corresponde à variação percentual entre o valor obtido com a Gasolina S50 em relação ao medido com a Gasolina S800. Onde a diferença observada não foi estatisticamente significativa, utilizou-se a legenda "s/dif."

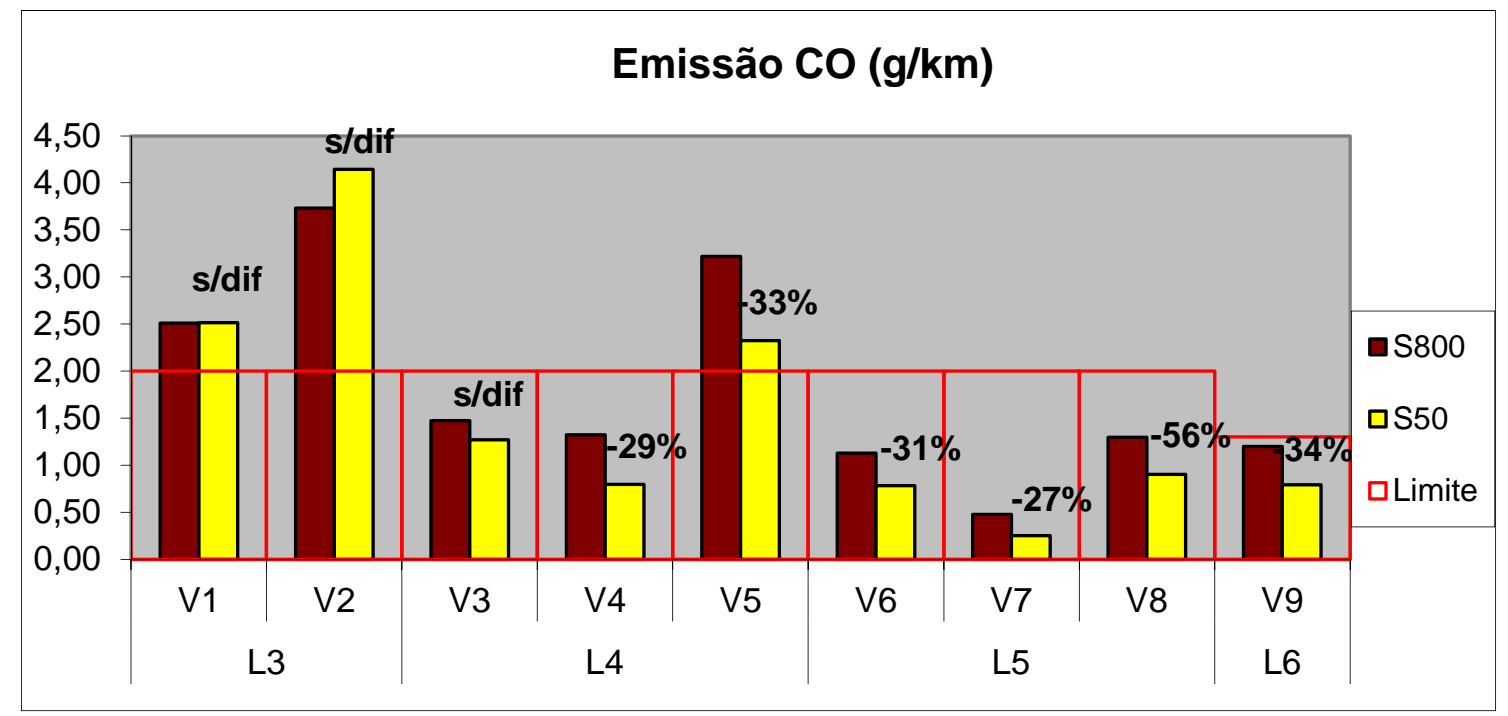

Figura 1: Emissões médias de CO dos veículos com as gasolinas de teste.

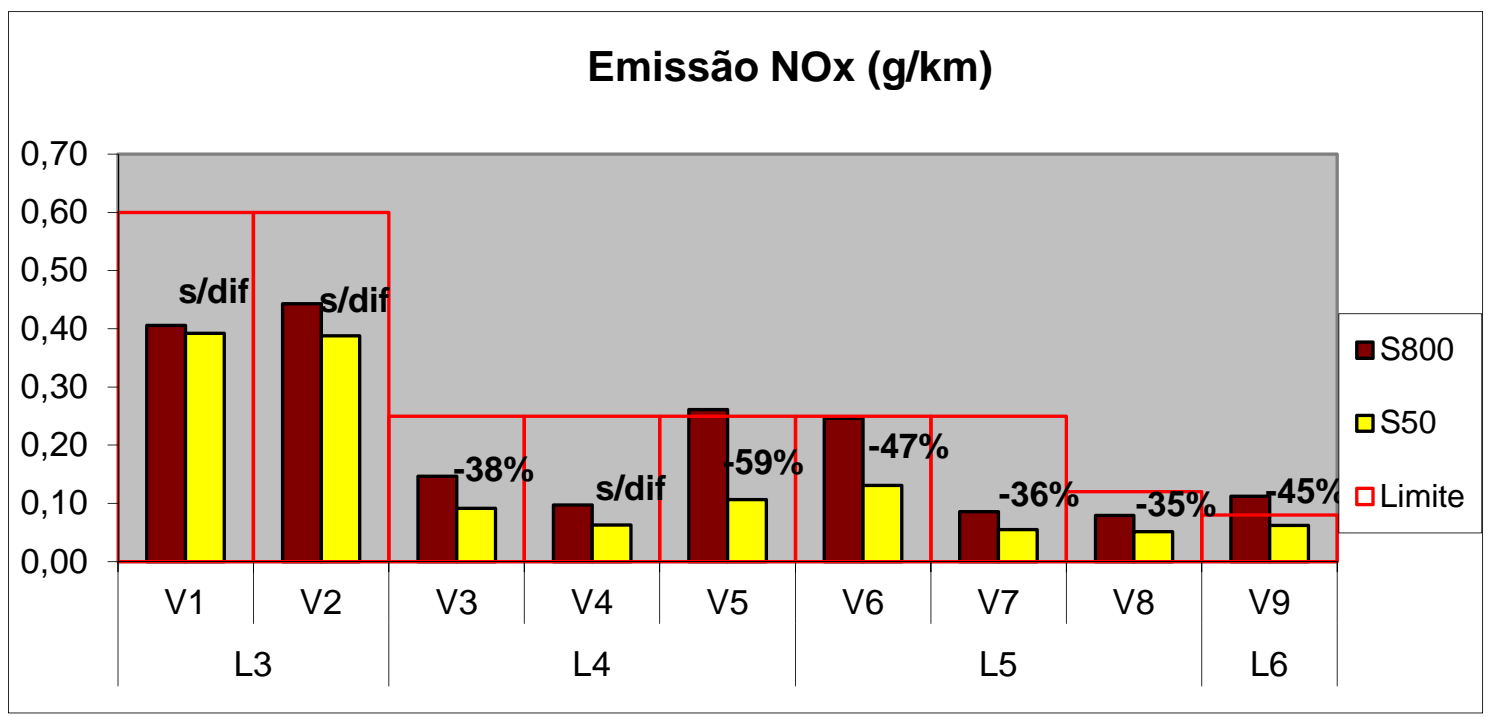

Figura 2: Emissões médias de NOx dos veículos com as gasolinas de teste. 


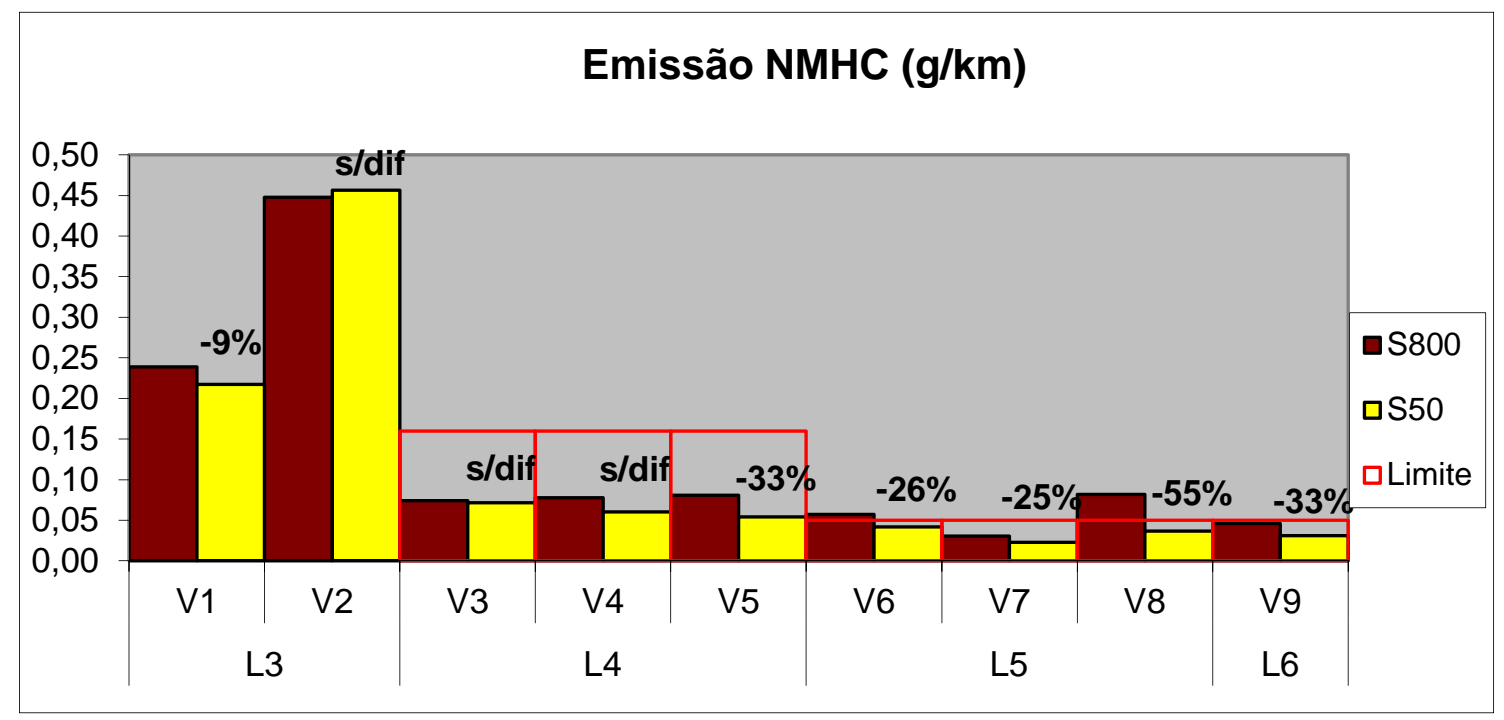

Figura 3: Emissões médias de NMHC dos veículos com as gasolinas de teste.

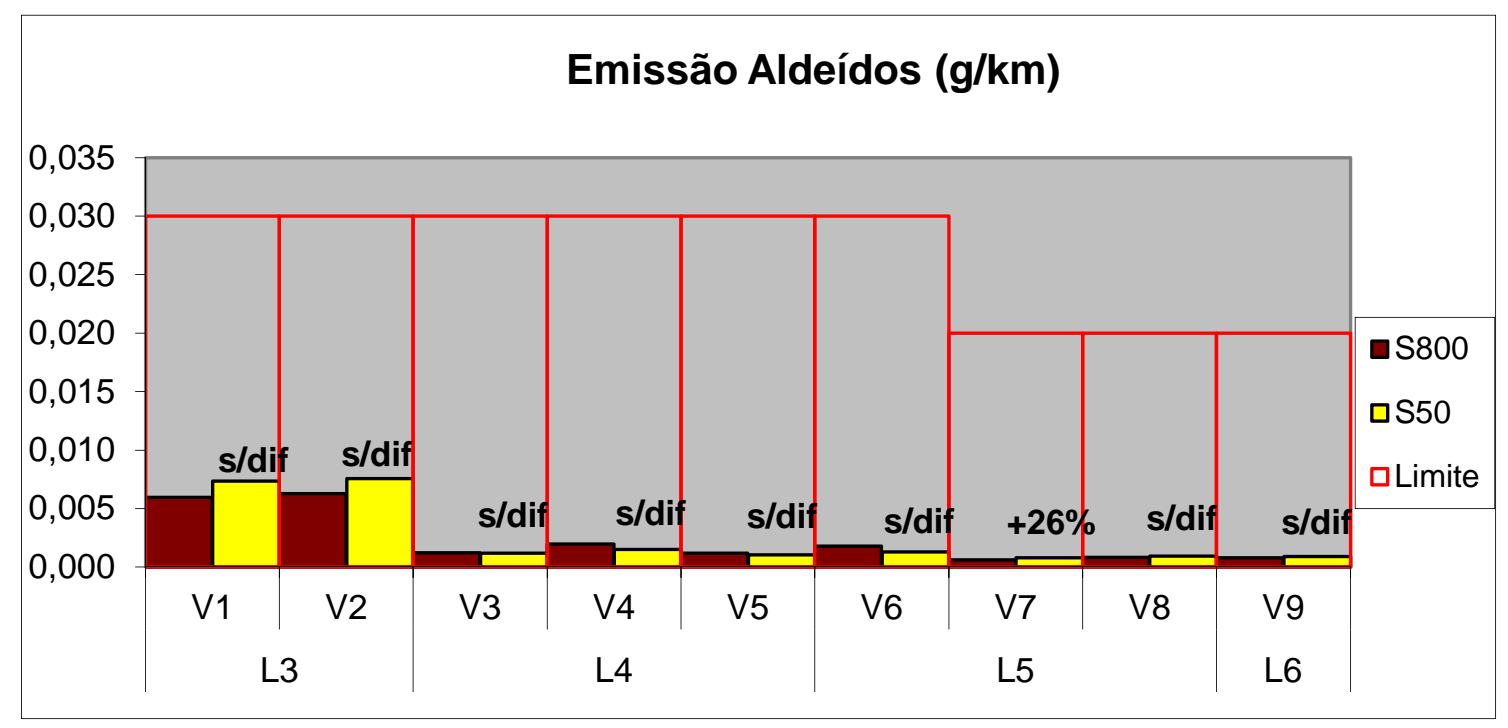

Figura 4: Emissões médias de Aldeídos dos veículos com as gasolinas de teste.

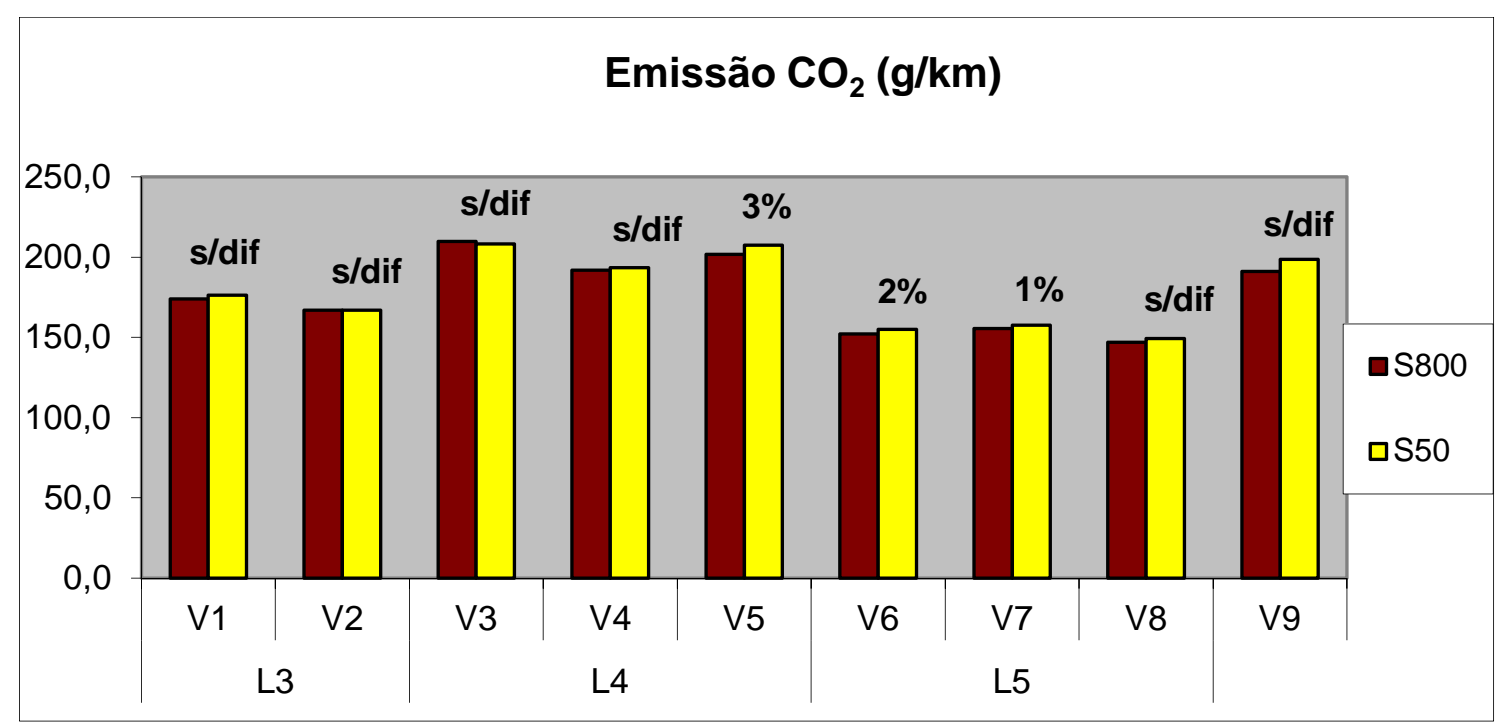

Figura 5: Emissões médias de $\mathrm{CO}_{2}$ dos veículos com as gasolinas de teste. 


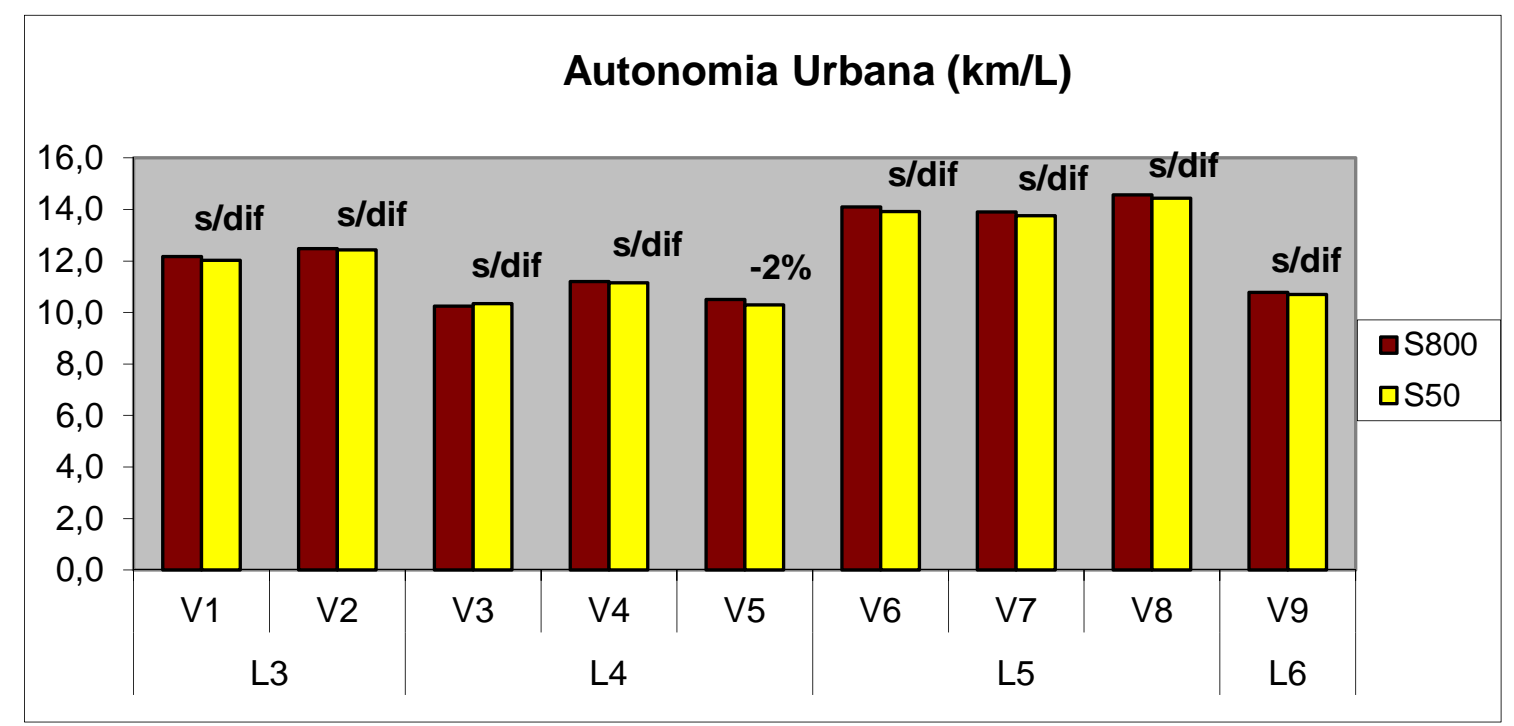

Figura 6: Autonomia urbana média dos veículos com as gasolinas de teste.

Em relação aos limites do PROCONVE, observa-se nas Figuras 1 e 2 que os veículos V1, V2 e V5 excederam os limites de CO com os dois combustíveis, enquanto os veículos V5 e V9 superaram o limite de NOx, porém somente quando abastecidos com a gasolina S800. Os resultados dos veículos V1, V2 e V5 podem ser atribuídos à deterioração natural do catalisador dos mesmos, pois a quilometragem inicial dos três veículos estava além da vida útil mínima de 80.000 km estabelecida pelo PROCONVE.

O fato do veículo importado V9 também ter violado o limite de NOx com a gasolina S800 se deve ao fato de sua tecnologia de controle de emissões ter sido desenvolvida tendo como pressuposto um teor de enxofre menor do que 50 ppm no combustível.

Em relação aos limites do PROCONVE para NMHC (fase L4 em diante), o mesmo não foi atendido pelos veículos V6 e V8, ambos da fase L5, quando abastecidos com gasolina S800 (Figura 3). Como a quilometragem inicial destes veículos ainda era baixa (14.000 km e $27.000 \mathrm{~km}$, respectivamente), suas manutenções periódicas estavam em dia e o teor de enxofre da gasolina utilizada era compatível com o da gasolina padrão de homologação (400 ppm), atribuiu-se o não atendimento a uma não conformidade de produção dos veículos.

Não houve violação do limite de aldeídos para nenhum dos veículos testados (Figura 4).

A comparação entre os resultados de emissões legisladas obtidos com a Gasolina S50 em relação aos da Gasolina S800, apontou para uma tendência de redução substancial, notadamente nos veículos a partir da fase L4 do PROCONVE. 
O uso da Gasolina S50 levou a uma diminuição da emissão de CO em 6 dos 9 veículos de teste, que variou entre $27 \%$ a $56 \%$ (Figura 1). Nos dois veículos mais antigos (L3) e em um dos L4, não houve diferença estatisticamente significativa.

Na emissão de NOx, a Gasolina S50 também obteve resultados melhores em 6 dos veículos (redução de 35\% a 47\%) e equivalente nos dois veículos L3 e em um dos L4 (Figura 2).

Para NMHC, novamente a emissão do poluente foi reduzida em seis veículos com a Gasolina S50 (de 9\% a 55\%) e se manteve em três deles, só que desta vez apenas em um dos veículos L3 e em dois L4 (Figura 3).

$\mathrm{Na}$ emissão de aldeídos, em apenas um caso foi detectada diferença estatisticamente significativa entre as gasolinas (26\%), porém tal fato não foi considerado relevante, tendo em vista o valor absoluto desta emissão ter sido bastante baixo.

Com relação à emissão de $\mathrm{CO}_{2}$ e à autonomia urbana, ambas ligadas à eficiência energética dos combustíveis, a grande maioria dos resultados foi equivalente. No entanto, em alguns poucos casos, houve uma discreta vantagem da Gasolina S800, de até $3 \%$ no $\mathrm{CO}_{2}$ em três dos veículos e de $2 \%$ na autonomia urbana de apenas um deles.

\section{CONCLUSÕES}

A utilização da Gasolina S50 trouxe clara vantagem quanto à redução da emissão de poluentes legislados, notadamente nos veículos com tecnologias de controle mais novas. Atribui-se o fato à expressiva redução do teor de enxofre no combustível, elevando a eficiência dos catalisadores automotivos.

Sabe-se que a redução do teor de enxofre da gasolina foi estabelecida pelo PROCONVE com o objetivo precípuo de que os veículos possam utilizar tecnologias mais avançadas para atender aos novos limites de emissões da fase L6. De fato, os testes efetuados no veículo importado V9, demonstraram que a composição do combustível foi essencial para que o mesmo já atendesse aos limites que entrarão em vigor em 2014.

No entanto, observa-se que se por um lado o novo combustível foi concebido para trazer um benefício no longo prazo, permitindo a utilização de tecnologias automotivas mais limpas, por outro lado, sua introdução provocará um impacto significativo já no curto 
prazo, com reduções expressivas nas emissões de CO, NOx e NMHC. Em aldeídos, não há expectativa de ganhos relevantes devido à nova composição da gasolina.

Com relação à emissão de $\mathrm{CO}_{2}$ e à autonomia urbana, ambas ligadas à eficiência energética do binômio veículo-combustível, observou-se que em alguns testes efetuados houve uma vantagem bastante discreta da gasolina S800. No entanto o pequeno número de casos e as mínimas diferenças observadas não permitem afirmar que isso seja uma tendência.

Cabe salientar ainda que a introdução da gasolina S50 permitirá a generalização de tecnologias automotivas mais eficientes, como a de veículos GDI (injeção direta de combustível), o que conduzirá a uma melhoria da eficiência global da frota, na medida em que ela for renovada.

\section{REFERÊNCIAS}

[1] CONSELHO NACIONAL DO MEIO AMBIENTE, Resolução CONAMA nº̄18 de 6 de maio de 1986.

[2] MMA - MINISTÉRIO DO MEIO AMBIENTE, 2011, $1^{o}$ Inventário Nacional de Emissões Atmosféricas por Veículos Automotores Rodoviários - Relatório Final, Brasília, DF, Brasil.

[3] CONSELHO NACIONAL DO MEIO AMBIENTE, Resolução CONAMA n 415 de 24 de setembro de 2009

[4] AGÊNCIA NACIONAL DE PETRÓLEO,GÁS NATURAL E BIOCOMBUSTÍVEIS, Resolução ANP nº 6, de 24 de fevereiro de 2005.

[5] AGÊNCIA NACIONAL DE PETRÓLEO,GÁS NATURAL E BIOCOMBUSTÍVEIS, Resolução ANP n ${ }^{\circ} 21$ de 02 de julho de 2009.

[6] AGÊNCIA NACIONAL DE PETRÓLEO,GÁS NATURAL E BIOCOMBUSTÍVEIS, Resolução ANP n ${ }^{\circ} 57$ de 20 de outubro de 2011

[7] AGÊNCIA NACIONAL DE PETRÓLEO,GÁS NATURAL E BIOCOMBUSTÍVEIS, Resolução ANP no 38 de 09 de dezembro de 2009.

[8] VICENTINI, P. C., 2001, "Influência do Teor de Enxofre da Gasolina nas Emissões de Escapamento de Veículos Leves do Ciclo Otto”, In: XI Simpósio Internacional de Engenharia Automotiva, SP, Brasil.

[9] MELO, T. C. C., VICENTINI, P. C., BENVENUTTI, L. H. et al.., 2004, "Influência do Teor de Enxofre da Gasolina Brasileira nas Emissões de Escapamento de um Veículo", Society of Automotive Engineers, paper 2007-01-398, São Paulo, SP, Brasil.

[10] SÁ, R.A.B., SILVA R.M.C.F., DAUZACKER E.R., 2004, "Mathematical Model to Predict the Otto Cycle Vehicles Exhaust Emissions from Automotive Gasoline Composition", Society of Automotive Engineers, paper SAE 2004- 01 - 2902, São Paulo, SP, Brasil. 
[11] MELO, T. C. C., CARVAlHO, R.N., SÁ, R.A.B. e CARDOSO, M.J.B., 2009, "Manutenção e Combustível Adequados - Garantia da Durabilidade de Emissões?", SIMEA 2009, São Paulo, SP, Brasil.

[12] SÁ, R.A.B., MElO, T. C. C., CARVAlHO, R.N., CARDOSO, M.J.B., ZOTIN, F.M.Z.e NEUMANN, R., 2011, "Manutenção e Combustível Adequados - Garantia da Durabilidade de Emissões? Parte 2 - Novas Evidências", SIMEA 2011, São Paulo, SP, Brasil.

[13] INSTITUTO BRASILEIRO DO MEIO AMBIENTE E DOS RECURSOS NATURAIS RENOVÁVEIS - IBAMA, 2010, Instrução Normativa $n^{\circ}$ 6, de 8 de junho de 2010, Brasília, DF, Brasil.

[14] ASSOCIAÇÃO BRASILEIRA DE NORMAS TÉCNICAS, Veículos rodoviários automotores leves - Determinação de Hidrocarbonetos, Monóxido de Carbono, Óxidos de Nitrogênio e Dióxido de Carbono no gás de escapamento - ABNT NBR 6601, setembro de 2012.

[15] ASSOCIAÇÃO BRASILEIRA DE NORMAS TÉCNICAS, Veículos rodoviários automotores leves - Determinação da Emissão de Aldeídos e Cetonas contidas no gás de escapamento, por Cromatografia Líquida - Método DNPH - ABNT NBR 12026, abril de 2009.

[16] ASSOCIAÇÃO BRASILEIRA DE NORMAS TÉCNICAS, Veículos rodoviários automotores leves - Medição do consumo de combustível - Método de Ensaio - ABNT NBR 7024, março de 2010. 